\title{
ResearchOnline@JCU
}

This is the author-created version of the following work:

Harvey, Nichole, and Holmes, Colin A. (2012) Nominal group technique: an effective method for obtaining group consensus. International Journal of Nursing Practice, 18 (2) pp. 188-194.

Access to this file is available from:

https://researchonline.jcu.edu.au/22604/

Please refer to the original source for the final version of this work:

http://dx.doi.org/10.1111/j.1440\%2D172X.2012.02017.x 


\begin{abstract}
This paper aims to demonstrate the versatility and application of nominal group technique as a method for generating priority information. Nominal group technique was used in the context of four focus groups involving clinical experts from the emergency department (ED) and obstetric and midwifery areas of a busy regional hospital to assess the triage and management of pregnant women in the ED. The data generated was used to create a priority list of discussion triggers for the subsequent Participatory Action Research Group. This technique proved to be a productive and efficient data collection method which produced a hierarchy of perceived information and identified real world problems. This information was vital in initiating the participatory action research project and is recommended as an effective and reliable data collection method, especially when undertaking research with clinical experts.
\end{abstract}

Key Words: decision-making, clinical nursing research; data collection; focus groups; health services research. 


\section{NOMINAL GROUP TECHNIQUE (NGT): AN EFFECTIVE METHOD FOR OBTAINING GROUP CONSENSUS}

\section{Introduction}

Nominal group technique (NGT), along with the Delphi survey ${ }^{1}$, is one of the most commonly used formal consensus development methods ${ }^{2-6}$. Both obtain the views of experts on a given topic, and bring about group consensus, but unlike the Delphi technique, the key feature of NGT is structured face-to-face meetings. The intent of this paper is not to compare these two methods, but to demonstrate that NGT provides an orderly procedure for obtaining relevant and reliable qualitative information from a group of experts, within a focus group setting $^{7}$. NGT can be used within the context of a focus group, and elicits responses from each group member to predetermined and structured questions ${ }^{8}$. Some authors have argued that this enhances the value of focus groups as sources of information, ${ }^{9}$ by generating data about a specific topic or question, and prioritizing problems and issues through group discussion. It allows disparate ideas on a subject of shared interest to be expressed and collated, with a view to identifying areas of consensus and establishing priorities for change. The collaborative nature of NGT increases the stakeholders' ownership of the ensuing research and therefore increases the likelihood of changing clinical practice and policy ${ }^{10}$. To provide a practice context for the use of NGT, this paper begins with a brief overview of the first authors' doctoral study. It then provides a review of the literature on the use of NGT in healthcare research, concluding with a consideration of its strengths and weaknesses, as exemplified in the study. Finally, the paper explains step-by-step the use of NGT, with examples drawn from the doctoral study. 


\section{Overview of research project}

NGT was used in the context of an action research student which assessed the triage and management of pregnant women entering the emergency department (ED) of a busy regional hospital in Queensland, Australia. A key purpose of action research is to produce strategies and practical knowledge useful to people in everyday life ${ }^{11}$ and NGT therefore seemed ideally suited to the study. Furthermore, it offered the prospect of a collaborative process, consistent with the critical theory standpoint of the researcher, which would give all participants a voice, and generate the required issues and priorities for change. Before commencing the study, ethical approval was obtained from the research site's Human Research Ethics Committee (HREC) and James Cook University’s HREC. The research was successfully completed, produced a better understanding of how pregnant women are assessed and managed in the ED, and resulted in the creation of better treatment protocols.

\section{Literature review}

NGT was developed in the 1960s as a procedure to facilitate effective group decisionmaking in social psychological research ${ }^{7}$, and has since been employed in a wide range of fields including education and health. Internationally, there have been a number of healthcare studies that used NGT. A New York study by Bajracharya ${ }^{12}$, for example, used NGT to clarify issues relating to perceived barriers to screening for colorectal cancer from a primary health care professionals' perspective and to compile a list of suggested strategies to reduce these barriers. In another US study Chasens and Olshansky ${ }^{13}$ developed a priority list of problems that people with type 2 diabetes associated with sleeplessness. They found NGT to be an excellent process in generating and clarifying ideas and providing a voice to all participants. In Scotland, Carney et al. ${ }^{14}$ described NGT as a way of bridging the gap between researchers and clinicians. They used NGT to identify what the needs of community 
nurses were and found the process to be effective in providing direction in the early stages of research and ideal when working with clinicians. In a British study of palliative care, Aspinall et al. ${ }^{15}$ used NGT in focus groups exploring the issues facing patients, professionals and bereaved relatives. The researchers reported that little consensus emerged as to the most important issues to be addressed in palliative care, and thought this might be because of the modifications that they made in view of the highly sensitive and emotionally charged nature of the topic. The study by Aspinall et al. ${ }^{15}$ involved 10 groups and a total of 75 participants, and they subsequently endorsed the observation by Vella et al. ${ }^{10}$ that using NGT to prioritise issues may be increasingly difficult as the size and number of groups increases. Although they suggested that NGT needs further development in its relation to sensitive topics, they concluded that it had been successful for the purposes of their study. Perry and Linsley ${ }^{16}$, also UK researchers, used NGT to evaluate mental health nursing students' experience of interpersonal skills assessment with the aim of improving the curriculum. The ranked list of items generated by the study provided them with direction for the development of a questionnaire for a further study on the topic. A Dutch study, ${ }^{17}$ included NGT as an element in a large mixed methods study of professionalism among General Practitioners. The researchers used it to establish the content validity of a measure of professionalism, and argued that it increased the reliability of their results. A group of European researchers ${ }^{18}$ successfully used NGT in a study designed to construct an international diagnostic framework for irritable bowel syndrome appropriate to primary care. Cook and Birrel ${ }^{19}$ used NGT in combination with the Delphi method to investigate the role of occupational therapists in the care of people with psychosis, and specifically sought to establish a consensual account based on statements prepared in advance by the researchers. In respect of NGT, it was concluded that its validity and effectiveness would reflect the level of expertise of the participants, and that choosing the membership of the group, and judging the degree of preparation members 
required, were important for its success. Tuffrey-Wijne et al. ${ }^{20}$ conducted a study which successfully used NGT with case vignettes to elicit the views of people with intellectual disabilities on sensitive issues, such as end-of-life care provision.

In Australia NGT is used as a reliable data collection method where group consensus is required and also as a means to determining research priorities in healthcare. For example Robotin et al. ${ }^{21}$ used NGT to define seven topics for pancreatic cancer research priorities and in a similar study Redman et al. ${ }^{22}$ used NGT to determine research priorities for the NHMRC National Breast Cancer Centre. Another Australian study ${ }^{23}$ used NGT to canvass insights from clinicians as part of a mixed methods investigation of nursing documentation. In a Queensland study, ${ }^{24,}{ }^{25}$ NGT was used to explore what psychological factors may influence the duration of breastfeeding. Four groups were created; three constituted breastfeeding mothers and the final group consisted of lactation experts or midwives. A total of 53 items were identified as influencing the duration of breastfeeding. NGT was used in a Victorian study $^{26}$ to successfully evaluate changes to teaching and learning in a perioperative course, and in South Australia ${ }^{27}$ it was used at a forum involving key stakeholders to discuss, debate and rank recommendations that impacted on registered nurses' ability to care for older Australians.

\section{Why use NGT?}

The commonest applications of NGT are: problem identification by helping generate the right research questions; development of solutions; and, establishing priorities for action. Authors that developed this technique, such as Van de Ven and Delbecq ${ }^{6}$ regarded NGT as a problem-solving method, based on the development of a consensual depiction of the problem, and it has principally been used in the present study as a means of problem clarification. Its 
value in this regard was affirmed by van Teijlingen et al. ${ }^{28}$, who reviewed the merits and applications of using NGT to explore and collate expert opinion. They concluded that it has validity, provided the facilitator does not attempt to overcome diversity of opinion in order to create artificial consensus. In bringing together a diverse group of individuals from different health disciplines and different clinical settings, the present study provided a unique and valuable opportunity for mutual clarification of issues important to all parties, irrespective of the level of consensus.

In summary, there were a number of persuasive reasons for using NGT for this study. Firstly, involving experts in a face to face structured meeting enabled first-hand information to be obtained from those working in the 'front line' of the clinical areas involved. Capitalising on the experience and expertise of clinicians in this way, underscored our claim that the findings are clinically relevant. It was also believed that meeting expert clinicians face-to-face would help the researcher develop rapport with potential candidates for the Action Research Group, which was central to the subsequent conduct of the research. This was deemed more important than the participant anonymity which was offered by the Delphi technique $^{29}$, and when the Action Research Group was established, approximately $80 \%$ of its members had attended the focus groups.

A number of other practical considerations supported the use of NGT. Firstly, it is time efficient ${ }^{30}$, being a single occasion process which nonetheless provides an opportunity to acquire a substantial amount of information in a relatively short time. This was a significant consideration, since the research involved very busy hospital clinicians with limited availability. The focus groups lasted from one to one and half hours, and the group sizes ranged from 5-16 people, with a typical group comprising 7-10 experts. Ideal group size is 
usually 6-12 people. ${ }^{31}$ Secondly, NGT is money efficient ${ }^{30}$ in that it entails little direct expenditure. In this case, the venue was available without charge, and a small grant enabled refreshments to be provided, which appeared to encourage a relaxed and sharing atmosphere. Thirdly, NGT required little preparation by participants, again an important consideration for stressed and busy clinicians who would be reluctant to participate if it entailed pre-reading or other tasks such as completing questionnaires. This meant that senior clinicians with demanding work schedules agreed to participate, an important consideration in view of findings, supported in this study, that the level of expertise of the group is crucial to its success and the validity of the data it generates ${ }^{19}$. Fourthly, NGT allows for in-session completion and immediate dissemination of results to the group, promoting satisfaction with participation. In this study, information became available to the group as it was created and the groups agreed that this gave them a sense of achievement at the conclusion of the session.

The final two compelling reasons for using NGT in this study were its capacity to give equal representation to all group members and to create an environment conducive to initiation of change ${ }^{31}$. These are key considerations from a critical action researcher's perspective. In this research, equal representation was important in ensuring that one health discipline did not dominate the process, nor dominant group members impose their opinions and views upon more reticent colleagues ${ }^{32}$. NGT lessened the impact of unhelpful group dynamics and encouraged participation from all group members, regardless of their discipline or level of appointment. Finally, it is a sine qua non of action research that participation takes place in an atmosphere conducive to change, and NGT proved effective in creating a passion among the expert clinicians to improve care. It allowed all participants to voice their opinion and feel empowered to contribute information that would lead to the development of better treatment protocols. 


\section{The NGT protocol: A step by step approach}

The protocol (Figure 1) for conducting NGT for this study was adopted from Potter et al. ${ }^{30}$ Each focus group began with the first step in the protocol, namely a brief introduction, followed by an explanation of the purpose of the session. Additional 'information giving' in the introductory phase included: distributing the information sheet to participants and gaining consent; informing the group that the study had ethical approval and support from key stake- holders such as the Directors of Nursing and Medicine; and, establishing ground rules around confidentiality, respect and protection of participants' identity. Consent was also gained to make an audiotape recording of the session, primarily for the purpose of the researcher's self-evaluation.

The composition of the four groups respectively was: ED residents, registrars and physicians ( $n=10)$; obstetric residents, registrars and consultants $(n=5)$; hospital mid- wives ( $n=7)$; and ED nurses $(n=16)$. Two groups were conducted in a meeting room in the ED with around the room open seating, and the other two groups met in an auditorium with tiered seating. The tiered seating arrangement was not ideal, but this was the only venue available at that time. Using NGT was helpful in overcoming some of the barriers attributed to tiered seating (i.e. NGT allowed each participant to contribute regardless of where they were seated); however, ideally a semi-circle arrangement would have been preferred, as is supported by Rosenfield et al. ${ }^{34}$

The second step in the protocol was the silent generation of ideas. Each participant was provided with a pen and booklet with a question at the top of each page (Box 1). They were asked to write down all their ideas when considering each question, and not to consult or discuss their ideas with others at this stage. This was generally an effective procedure, with 
only the occasional comment being made between participants and one participant seeking clarification on a question. A couple of minutes was allocated to each question, and this proved to be adequate, since all participants had stopped writing at the end of the period allotted and were ready to move onto sharing their ideas.

The third step involved inviting participants to share their ideas by using the 'round robin' technique. This proved successful, and continued until all ideas had been presented. Some participants were keen to start discussing items as soon as they were contributed, but were reminded that no debate about individual contributions should occur until all the ideas had been recorded. It was important that this control was maintained, so that each participant in the group had the opportunity to voice their opinion without others in the group modifying or rejecting their view before group discussion had occurred. Ideas were recorded on a whiteboard for three of the groups, using the exact words spoken by the participants. This helped create an atmosphere where the participants' interests were the main focus and not that of the researcher, helped develop an understanding from the participants' perspective, and represented the data in the participants' terms. For the fourth group, there was access to a laptop, data projector and large screen, and the information was typed verbatim. This was a time efficient method, with the added benefit of providing an electronic record of the session.

The fourth step in the protocol was group discussion. Once all the responses were listed, the participants were invited to seek verbal explanations or further details about any of the ideas that their colleagues had produced that may not be clear to them. During this stage, it was important to enable participants to contribute to the discussion but not allow one person to dominate the discussion. It was also imperative that the process be as 'value 
neutral' as possible, avoiding judgment and criticism. This was not as difficult as first anticipated, although the smaller group, of five participants, proved more challenging because it included both dominant and reticent personalities. Although the dominant participants were knowledgeable and keen to contribute, the researcher repeatedly sought the engagement of the quieter voices, and a reasonable balance was achieved. Because everyone shared the common aim of improving care for pregnant women, they were willing to discuss and negotiate with each other as to what they believed were the problems and possible solutions. Furthermore, since the focus groups provided an opportunity for participants to share and contribute to this aim, they felt they were part of the solution, rather than the problem, which is a common perception in a systems- dominated environment.

The final step in the protocol is voting and ranking, which involved asking each group to prioritise their recorded ideas about each question discussed. As each question was discussed, the group was asked to negotiate what they regarded as the top four priority ideas or issues. One group, when first asked to rank their list, had one person nominate a particular item which was then dis- cussed and agreed not to be their first priority, and another idea on the list was then considered. Eventually, the group would say 'yes, yes that's right now, yes that's the way it is'. Overall, the process of ranking worked well, and the priority lists reflected group consensus. On reviewing the data upon completion, the four highest priority items were remarkably similar across all groups. An illustration has been given in Table 1 to illustrate the ranking process for question 1 only. The information obtained by using this process was subsequently taken to the Participatory Action Research Group, so that strategies to improve care could be developed that reflected 'real' areas of priority by clinicians. 


\section{Conclusion and recommendations}

The use of NGT as an information generating tool and consensus development method was highly effective and efficient in this research study. There were some limitations; firstly, the small size of the obstetric group. It would have been better to have had at least 6-12 participants. Secondly, the tiered auditorium used for two of the groups also was not ideal and a flat round circle environment would have been preferred. Finally, a mixed focus group of experts (i.e. midwives, ED and obstetric doctors, and ED nurses) was not conducted to determine the effect of having nurses, midwives, doctors and specialists in the one group and how this may have influenced the data generated. This was not considered necessary in this research project, because the methodology of action research provided the opportunity to discuss issues as a mixed group with the subsequent establishment of the heterogeneous Participatory Action Research Group. Had action research not been used as the overall methodology, it would have been valuable to conduct a heterogeneous group using NGT as well.

There were many advantages of using NGT to collect preliminary data. The benefit of being able to meet experts face-to-face was important in establishing the collaborative relationships consistent with the methodological principles of participatory action research. NGT addressed the topic in a comprehensive fashion and enabled a substantial amount of data to be obtained in a relatively short period of time from a group of busy hospital clinicians. The absence of preliminary tasks for participants also helped to achieve good numbers of experts at each focus group. Overall, NGT married well with the critical action research approach. It was collaborative; involved a group of experts trying to understand and improve real world practices; gave each participant a voice and the opportunity to contribute; involved clinical experts so that information was clinically 
relevant and participant focused; and, provided an environment conducive to change. The use of NGT proved a successful data collection method in the context of this study, and can be recommended for inclusion in participatory action research projects and clinically based research.

\section{Acknowledgment}

This study was supported by a graduate research scheme grant from James Cook University, Australia. We would also like to thank Dr Jane Mills, James Cook University, for kindly reviewing this manuscript prior to submission, and the expert clinicians who willingly participated in this study. 


\section{References}

1. Hutchings A, Raine R. A systematic review of factors affecting the judgments produced by formal consensus development methods in health care. Journal of Health Services Research \& Policy 2006; 11: 172-179.

2. $\quad$ Delbecq AL, Van de Ven AH, Gustafson DH. Group techniques for program planning a guide to nominal group and delphi processes. Dallas: Scott-Foresman 1975.

3. Freeman T. 'Best practice' in focus group research: Making sense of different views. Journal of Advanced Nursing 2006; 56: 491-497.

4. Gallagher M, Hares T, Spencer J, Bradshaw C, Webb I. The nominal group technique: A research tool for general practice? Family Practice 1993; 10: 76-81.

5. Delbecq AL. The nominal group as a technique for understanding the qualitative dimensions of clinet needs. In: Bell RA, (ed). Assessing health and human service needs. New York: Human Sciences Press, 1983; 210-218.

6. Van de Ven AH, Delbecq AL. The nominal group as a research instrument for exploratory health studies. American Journal of Public Health 1972; 62: 337-342.

7. Van de Ven AH, Delbecq AL. Nominal versus interacting group process for committee decision-making effectiveness. Academy of Management Journal 1971; 14: 203-212.

8. Jamieson M, Griffiths R, Jayasuriya M. Developing outcomes for community nursing: The nominal group technique. Australian Journal of Advanced Nursing 1998; 16: 14-19.

9. Langford B, Schoenfeld G, Izzo G. Nominal grouping sessions vs. focus groups. Qualitative Market Research 2002; 5: 58-70.

10. Vella K, Goldfrad C, Rowan K, Bion J, Black N. Use of consensus development to establish national research priorities in critical care. British Medical Journal 2000; 320: 976-980.

11. Reason P, Bradbury H. Handbook of action research: The concise paperback edition. London: Sage Publications, 2006.

12. Bajracharya SM. An assessment of the perceived barriers and strategies to promoting early detection of colorectal cancer: A practitioners' perspective. International Quarterly of Community Health Education 2006; 26: 23-44.

13. Chasens ER, Olshansky E. Daytime sleepiness, diabetes, and psychological well-being. Issues in Mental Health Nursing 2008; 29: 1134-1150.

14. Carney O, McIntosh J, Worth A. The use of the Nominal Group Technique in research with community nurses. Journal of Advanced Nursing 1996; 23: 1024-1029.

15. Aspinall F, Hughes R, Dunckley M, Addington-Hall J. What is important to measure in the last months and weeks of life? A modified nominal group study. International Journal of Nursing Studies 2006; 43: 393-403.

16. Perry J, Linsley S. The use of the nominal group technique as an evaluative tool in the teaching and summative assessment of the inter-personal skills of student mental health nurses. Nurse Education Today 2006; 26: 346-353.

17. van de Camp K, Vernooij-Dassen M, Grol R, Bottema B. Professionalism in general practice: Development of an instrument to assess professional behaviour in general practitioner trainees. Medical Education 2006; 40: 43-50.

18. Rubin G, De Wit N, Meineche-Schmidt V, Seifert B, Hall N, Hungin P. The diagnosis of IBS in primary care: Consensus development using nominal group technique. Family Practice 2006; 23: 687-692. 
19. Cook S, Birrell M. Defining an Occupational Therapy intervention for people with psychosis. The British Journal of Occupational Therapy 2007; 70: 96-106.

20. Tuffrey-Wijne I, Bernal J, Butler G, Hollins S, Curfs L. Using nominal group technique to investigate the views of people with intellectual disabilities on end-oflife care provision. Journal of Advanced Nursing 2007; 58: 80-89.

21. Robotin M, Jones S, Biankin A, et al. Defining research priorities for pancreatic cancer in Australia: Results of a consensus development process. Cancer Causes and Control 2010; 21: 729-736.

22. Redman S, Carrick S, Cockburn J, Hirst S. Consulting about priorities for the NHMRC National Breast Cancer Center: How good is the nominal group technique? Australian and New Zealand Journal of Public Health 1997; 21: 250-256.

23. Cheevakasemsook A, Chapman Y, Francis K, Davies C. The study of nursing documentation complexities. International Journal of Nursing Practice 2006; 12: 366-374.

24. O'Brien M, Buikstra E, Fallon T, Hegney D. Exploring the influence of psychological factors on breastfeeding duration, phase 1: Perceptions of mothers and clinicians. Journal of Human Lactation 2009; 25: 55-63.

25. O’Brien ML, Buikstra E, Fallon T, Hegney D. Strategies for success: A toolbox of coping strategies used by breastfeeding women. Journal of Clinical Nursing 2009; 18: 1574-1582.

26. Richardson-Tench M, Martens E. From systems to tissues: A revolution in learning in perioperative education. Education for Health 2005; 18: 22-31.

27. Cheek J, Ballantyne A, Jones J, Roder-Allen G, Kitto S. Ensuring excellence: An investigation of the issues that impact on the registered nurse providing residential care to older Australians. International Journal of Nursing Practice 2003; 9: 103-111. 28. van Teijlingen E, Pitchforth E, Bishop C, Russel E. Delphi method and nominal group techniques in family planning and reproductive health research. Journal of Family Planning and Reproductive Health Care 2006; 32: 249-252.

29. Holey E, Feeley J, Dixon J, Whittaker V. An exploration of the use of simple statistics to measure consensus and stability in Delphi studies. BMC Medical Research Methodology 2007; 7: 52-62.

30. Potter M, Gordon S, Hamer P. The nominal group technique: A useful consensus methodology in physiotherapy research. NZ Journal of Physiotherapy 2004; 32: 126-130.

31. Pastrana T, Radbruch L, Nauck F et al. Outcome indicators in palliative carehow to assess quality and success. Focus group and nominal group technique in Germany. Supportive Care in Cancer 2010; 18: 859-868.

32. Davis DC, Rhodes R, Baker AS. Curriculum revision: Reaching faculty consensus through the nominal group technique. Journal of Nursing Education 1998; 37: 326-328.

33. Gaskin S. A guide to nominal group technique (ngt) in focus-group research. Journal of Geographical Higher Education 2003; 27: 342-347.

34. Rosenfield P, Lambert S, Black R. Desk arrangement effects on pupil classroom behavior. Journal of Educational Psychology 1985; 77: 101-108 


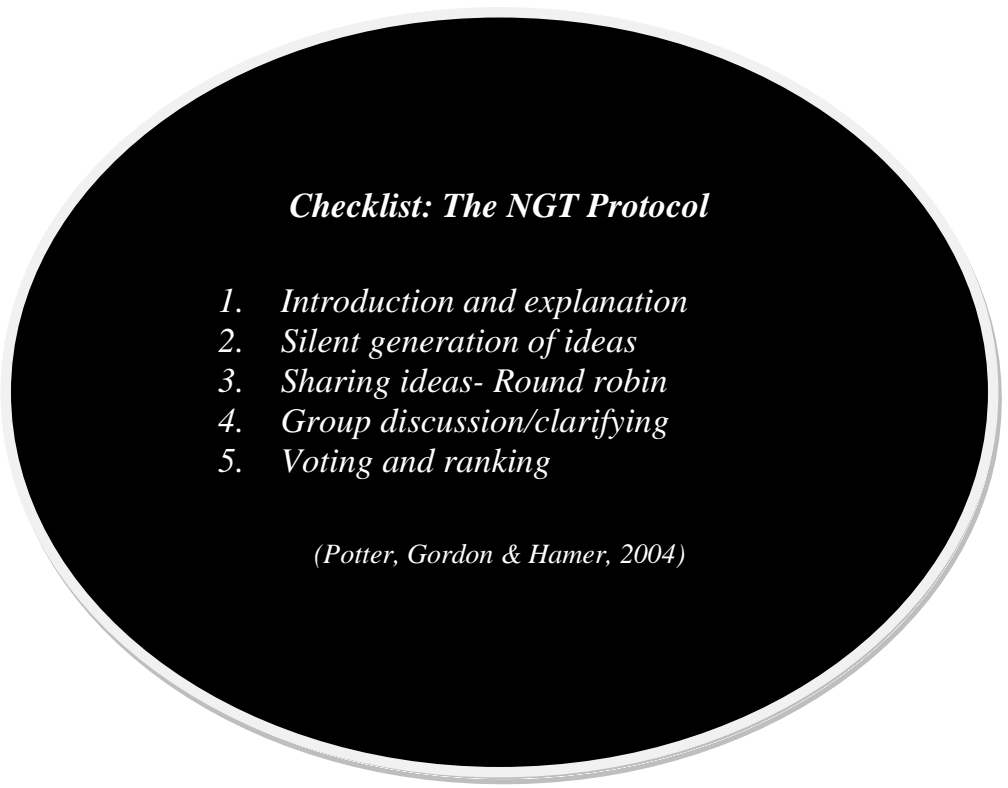

Box 1: The nominal group technique questions asked of the emergency department (ED) groups.

1. In your experience, what are the commonest reasons for pregnant women to present to the ED? Just write them down.

2. What is the normal process you follow when a pregnant woman presents to the department? Just write down the steps you would normally follow.

3. When do you consider referring a woman directly to the birth suite? Again just write down the types of presentations.

4. Are you using hospital or practice polices/guidelines when you make decisions about pregnant women in the ED? If so, can you write down the ones that influence your decision making?

5. What strategies and processes do you think would improve the triaging and management of pregnant women in ED?

6. Final question...Approximately how may pregnant women do you see in a week in the ED? (I am just trying to gauge whether this is relatively common or not). 
Table 2: List of ranked priorities generated by the four expert groups to question 1

\begin{tabular}{|c|c|c|c|c|}
\hline $\begin{array}{l}\text { Ranked } \\
\text { Number }\end{array}$ & ED Doctors & ED Nurses & Obstetricians & Midwives \\
\hline & $\begin{array}{l}\text { What are the } \\
\text { commonest } \\
\text { reasons for women to } \\
\text { present to the ED? }\end{array}$ & $\begin{array}{l}\text { What are the } \\
\text { commonest } \\
\text { reasons for women to } \\
\text { present to the ED? }\end{array}$ & $\begin{array}{l}\text { What are the } \\
\text { commonest } \\
\text { reasons you are } \\
\text { paged/ contacted by } \\
\text { the ED? }\end{array}$ & $\begin{array}{l}\text { What are the main } \\
\text { reasons women } \\
\text { get } \\
\text { referred/transferred } \\
\text { from the ED? }\end{array}$ \\
\hline 1 & $\begin{array}{l}\text { Early pregnancy } \\
\text { PV bleeding }\end{array}$ & PV Bleeding & $\begin{array}{l}\text { Threatened } \\
\text { miscarriage }\end{array}$ & $\begin{array}{l}\text { Pregnant - > } 20 \\
\text { weeks gestation } \\
\text { regardless of } \\
\text { problem }\end{array}$ \\
\hline 2 & Hyperemesis & Miscarriage & $\begin{array}{l}\text { Hyperemesis and/or } \\
\text { nausea and vomiting }\end{array}$ & $\begin{array}{lll}\text { Abdominal pain } \\
\text { labour }\end{array}$ \\
\hline 3 & $\begin{array}{l}\text { Follow-up } \\
\text { appointments for } \\
\text { Ultrasounds }\end{array}$ & $\begin{array}{l}\text { Abdo Pain (ectopic, } \\
\text { UTI) }\end{array}$ & $\begin{array}{l}\text { Postnatal - bleeding, } \\
\text { pain \& mastitis }\end{array}$ & $\begin{array}{l}\text { Gastro / nausea/ } \\
\text { dehydration }\end{array}$ \\
\hline 4 & $\begin{array}{l}\text { Trauma or } \\
\text { conditions which } \\
\text { are unrelated to } \\
\text { their pregnancy }\end{array}$ & Hyperemesis & $\begin{array}{l}\text { Did not want to rank } \\
a 4^{\text {th }} \text { item as they } \\
\text { considered the others } \\
\text { similar in priority }\end{array}$ & $\begin{array}{l}\text { Did not want to rank } \\
a 4^{\text {th }} \text { item as they } \\
\text { considered the others } \\
\text { similar in priority }\end{array}$ \\
\hline
\end{tabular}

ED, Emergency department; PV, per vagina; UTI, urinary tract infection 